\title{
Importance of early intervention in verapamil overdose - Case Report and antidotes review
}

\author{
Paweł Marzęda ${ }^{1,2, A-D \oplus}$, Małgorzata Drozd ${ }^{2, B-D} \oplus$, Michał Tchórz ${ }^{3, B, E-F} \oplus$, Karolina Kisiel ${ }^{2, C-D} \oplus$ \\ 1 Department of Pathophysiology, Medical University of Lublin, Poland \\ ${ }^{2}$ Student's Research Group at the Department of Toxicology, Medical University, Lublin, Poland \\ ${ }^{3}$ Department of Toxicology, Medical University, Lublin, Poland \\ A - Research concept and design, B - Collection and/or assembly of data, C - Data analysis and interpretation, \\ $D$ - Writing the article, E-Critical revision of the article, F- Final approval of the article
}

Marzęda P, Drozd M, Tchórz M, Kisiel K. Importance of early intervention in verapamil overdose. Case report and antidotes review. J Pre-Clin Clin Res. 2021; 15(3): 142-147. doi: 10.26444/jpccr/139037

\begin{abstract}
I Abstract
Introduction. Verapamil is a widely used cardiac drug. It belongs to the non-dihydropiridine subgroup of calcium channel blockers (CCBs), and is used mainly for the treatment of atrial dysrhythmias, hypertension or angina. In this article, we describe a case of poisoning with verapamil mixed with ethanol and review current treatment options. A 54-year-old female was admitted to the Toxicology Clinic by emergency medical services after ingesting sustained-release CCBs and ethanol in a suicidal attempt. The patient was successfully treated by administration of catecholamines and calcium, and the introduction of a high-dose insulin infusion (HDI).

Conclusions. This case report emphasizes that even in severe poisoning, early and proper intervention may prevent circulatory breakdown. It also summarizes treatment options in patients after verapamil overdose. Along with decontamination, administration of catecholamines and correcting electrolyte abnormalities, the main options are HDI and lipid emulsion therapy (LET).
\end{abstract}

\section{Key words}

overdose, calcium channel blocker, high-dose insulin, verapamil intoxication, toxicology, lipid emulsion therapy, antidotes

\section{INTRODUCTION}

Calcium channel blockers (CCBs) are divided into two main groups: dihydropyridines (DHPs) and non-dihydropyridines (non-DHPs). The names of DHPs usually include the '-pine' suffix, e.g. amlodipine, nicardipine or nifedipine. Verapamil and diltiazem belong to the non-DHP CCBs group. Calcium channel blockers form a large number of prescription medications used primarily as cardiovascular drugs; however, they may also be used for the treatment of other conditions for which the main indications are hypertension, angina, atrial dysrhythmias, vasospasms and migraine headaches $[1$, 2]. Every CCBs drug is well absorbed when taken orally and undergoes extensive hepatic first-pass metabolism [3].

Generally, CCBs should be considered as gating modifiers that stabilize inactivated voltage-gated L-type (slowly inactivating) calcium channels (LTCCs). As a result, they block $\mathrm{Ca}^{2+}$ ions flow through the cell membrane and slow down recovery from inactivation, which leads to use- or frequency-dependent inhibition [4]. This mechanism is responsible for both therapeutic and toxic effects. Therefore, the result of LTCCs is relaxation of vessels which causes vasodilatation, and in the case of non-dihydropyridines, inhibition of sinoatrial and atrioventricular nodes. The influx of calcium ions is also responsible for insulin secretion [5]. Various CCBs have a slightly different effect on glucose homeostasis [6, 7]; therefore, LTCCs located outside the cardiovascular system can potentially serve as novel targets for well-known drugs [4].

Address for correspondence: Małgorzata Drozd, Student's Research Group at the Department of Toxicology, Medical Universit, Lublin, Poland

E-mail: drozd.malg@gmail.com

Received: 18.04.2021; accepted: 16.06.2021; first published: 30.06.2021
A severe overdose of CCBs is relatively rare, but is potentially lethal. CCBs are the sixth among the top 25 substance categories that lead to death due to overdosage [8] (Tab. 1). Severe poisoning may be caused by suicidal ingestion, accidental over-ingestion, or exploratory ingestion by children [9]. Because of their narrow therapeutic index, CCBs can have adverse effects even when administered in low doses. Therefore, drug poisoning may happen not only in case of an overdose but also in prolong use of low doses of the drugs, especially in cases when metabolism and elimination alteration or drug interactions occur [10].

Verapamil causes a triple-negative effect, i.e. inotropic negative, chronotropic negative and dromotropic negative. It has affinity mainly to the myocardium and smooth muscles of blood vessels. Nevertheless, adverse effects of therapeutic doses of verapamil affect different tissues and may manifest as constipation, dyspepsia, headaches, flushing, gingival hyperplasia, peripheral oedema, hypotension or fatigue [11]. They can be life-threatening in cases of severe overdose. Poisoning with verapamil produces primarily cardiovascular toxicity combined with hypotension caused by vasodilatation, reduction in cardiac contractility and conduction disturbances, such as sinus bradycardia and decrease in atrioventricular node conduction [12]. In cases of verapamil poisoning in humans, hyperglycaemia and metabolic acidosis are observed. The reason for that may be the blockade of insulin release coupled with stress hormones release and induction of systemic insulin resistance [13, 14]. Acidosis may also be a result of CCBs interference with calcium-stimulated mitochondrial action, catabolism of glucose and induction of an intra-cellular carbohydratedeficient state $[3,15]$. In rare cases, verapamil poisoning may produce acute respiratory distress syndrome, which should 
Table 1. Top 25 categories of substances reported in fatal exposures (in order of the largest number of fatalites) [8]

\begin{tabular}{ll}
\hline & Substance/Category of substances \\
\hline 1 & Sedative/hypnotics/antipsychotics \\
\hline 2 & Opioids (pharmaceutical and illegal) \\
\hline 3 & Alcohols \\
\hline 4 & Stimulants and streets drugs \\
\hline 5 & Acetaminophen (alone) \\
\hline 6 & Calcium antagonists \\
\hline 7 & Beta blockers \\
\hline 8 & Antidepressants \\
\hline 9 & Selective serotonin reuptake inhibitors (SSRI) \\
\hline 10 & Acetaminophen (in combination) \\
\hline 11 & Hypoglycemic (alone) \\
\hline 12 & Sedating antihistamines \\
\hline 13 & Unknown drugs \\
\hline 14 & Cardiovascular drugs \\
\hline 15 & Anticonvulsants: Gamma aminobutyric acid and analogs \\
\hline 16 & Nonsteroidal antiinflammatory drugs \\
\hline 17 & Muscle relaxants \\
\hline 18 & Miscallaneous chemicals \\
\hline 19 & Fumes/Gases/Vapors \\
\hline 20 & Tricyclic Antidepressants (TCA) \\
\hline 21 & Acetylsalicyc Acid Alone \\
\hline 22 & Serotonin Norepinephrine Reuptake Inhibitors (SNRI) \\
\hline 23 & Miscallaneous anticonvulstants \\
\hline 24 & Angiotensin converting enzyme inhibitor \\
\hline 25 aninoids and analogs \\
\hline 10
\end{tabular}

be considered during patient examination $[16,17]$. When treating poisoning with slow-release forms of this drug, it is crucial to bear in mind that delayed effects may occur, among others, due to reduced gastric motility $[18,19]$. Overdoses with cardiovascular drugs are associated with significant morbidity and mortality. The combination of CCBs and $\beta$-blockers is particularly dangerous; nevertheless, there still is a shortage of strong recommendations for the management of such cases.

Moreover, apart from being familiar with interactions between different types of CCBs and other drugs, which may cause an increased risk of CCBs' toxicity, it is important to remember that CCBs interact with alcohol. Verapamil may elevate the blood concentration of ethanol and enhance the effects of alcohol via inhibition of ethanol elimination [20].

\section{CASE REPORT}

A 54-year-old female was brought by emergency medical services to the Toxicology Clinic at 22:00, reporting a suicide attempt by verapamil ingestion and ethanol poisoning. Anamnesis revealed that around 18:00 she consumed 40-60 tablets of $120 \mathrm{mg}$ sustained-release verapamil hydrochloride (Isoptin SR). Before arriving at the hospital, she had had an argument with her husband after which she drank alcohol and took the Isoptin tablets. She had easy access to the drug because she was prescribed this medication to treat supraventricular tachycardia attacks. The patient's weight was $52 \mathrm{~kg}$.
On admission at 22:00, patient was conscious, in a stable condition, fully responsive, verbally communicating logically, although in a distressed state. She admitted that she had consumed drugs in a suicide attempt. The first ECG showed steady sinus rhythm, heart rate (HR) of 95 beats per minute with non-specific intraventricular conduction defects and prolonged QT interval (502 ms); blood pressure - 150/90 mmHg. The blood tests, including complete blood count, venous blood gas analysis, kidney function test, liver function test, coagulation test, blood sodium, potassium calcium level tests and blood glucose test, remained within the reference range. Ethanol blood concentration - $2.28 \%$ o $(2.28 \mathrm{~g} / \mathrm{l} ; 0.228 \mathrm{~g} / \mathrm{dl})$.

Initially, gastric lavage was performed which did not produce the expected decontaminating effect. Afterwards, the patient was administered $50 \mathrm{~g}$ activated carbon via a nasogastric tube. In preparation for potential systemic shock, a central venous catheter was inserted into her right internal jugular vein.

From the moment of diagnosis, the prescribed antishock treatment was initiated in order to sustain life. In addition to fluids infusion, catecholamines (dobutamine and noradrenaline) were administered initially at a rate of $6 \mathrm{ml} / \mathrm{h}$ each. Afterwards, the specific treatment was initiated, which primarily involved the infusion of high insulin doses (HDI), starting with $25 \mathrm{U} / \mathrm{h}$ with $10 \%$ glucose, with simultaneous, repeated blood glucose level measures. Additionally, 10\% $\mathrm{CaCl}$ was administered i.v., and calcium blood levels were meticulously measured. The essential part of the treatment was maintaining physiological concentrations of electrolytes and glucose, disturbed by the drug overdose itself and by the medication administered. Therefore, doses were adjusted following haemodynamic parameters and results of laboratory tests. In order to prevent possible electrolyte disorders and secondary cardiac arrhythmias, potassium and magnesium were administered in initial doses of $2 \mathrm{~g}$ of magnesium sulfate $\left(\mathrm{MgSO}_{4}\right)$ and $3 \mathrm{~g}$ of potassium chloride (KCl), within 1-2 days, and via the intravenous route, followed by supplementation adequate to their serum levels. As a result of the all implemented treatment, the patient did not suffer circulatory insufficiency and secondary complications. Heart rate was maintained at a rate of 80 beats per minute, and BP at $105 / 70 \mathrm{mmHg}$, oxygen saturation at $96 \%$.

On the second and third days, the patient remained stable and the continuous infusion of dobutamine, noradrenaline, calcium and HDI with $10 \%$ glucose continued. HR oscillated around 80 beats per minute and BP around 130/60 $\mathrm{mmHg}$.

On the third day of hospitalization, the patient underwent psychological and psychiatric assessment. The patient denied previous psychiatric treatment, psychiatric disorders running in or present in the family, or alcohol abuse. These assessments did not mandate admission to a psychiatric unit.

During the next few days of hospitalization, the patient presented a tendency towards bradycardia and hypotension. HDI and calcium infusions were discontinued on the third day, noradrenaline on the fourth day and dobutamine on the fifth day of the hospital stay. Improvement in the patient's condition, normalization of clinical parameters and reduction of symptoms was possible thanks to the treatment and medical care provided.

After one week of hospitalization, the patient was discharged home in good condition with the referral for review in psychological/mental health clinic, and with the recommendation to discontinue consumption of alcohol. 


\section{DISCUSSION}

Overdosage of non-NDHPs CCBs can cause severe hypotension and systolic heart dysfunction resulting in a lethal outcome. The main goal in verapamil, as well as other CCBs poisoning management, is to stabilize the patient haemodynamically. Recently, guidelines for the treatment of such cases have emerged. As of the present day, there are Expert Consensus Recommendations that describe this problem in a wide manner. There are also Dutch practical recommendations and the guideline on the management of drug poisoning, which includes CCBs poisoning. However, in all of them, the level of evidence remains very low and the recommendations are in the form of expert opinion recommendations [21-23]. Therefore, treatment continues to be partially physician-dependent. Initial treatment of verapamil poisoning is primarily supportive and should be executed in accordance with standardized ALS protocols [24]. After securing the patient's airway, breathing and circulation, in haemodynamically stabilized patients an attempt at aggressive gastrointestinal decontamination should be considered. Methods depend on the length of time that passed since drug ingestion. Potential treatment options include gastric lavage, administration of activated charcoal, and whole bowel irrigation. The latter method may be useful in particular cases of patients who ingested sustained-release, enteric-coated drugs, drugs not adsorbed by activated charcoal, or if $>2 \mathrm{~h}$ have passed since drug ingestion [25]. If cardiovascular insufficiency is observed, then intravenous isotonic crystalloids and atropine should be applied to manage hypotension, low cardiac filling pressure and bradycardia. Critically ill patients may require a multitude of simultaneous therapies [26]. After the trial of every method mentioned above, vasopressors should be administered, sometimes in very high doses. CCBs overdose produces cardiovascular shock secondary to vasodilation of blood vessels; therefore, in such cases, norepinephrine administered via the central line is recommended.

High doses of calcium can be administered to manage some of the adverse effects such as hypotension and conduction disturbances. However, calcium is not likely to restore proper cardiovascular status. $\mathrm{Ca}^{2+}$ can be administered either as $10 \%$ calcium chloride $(\mathrm{CaCl})$ in boluses of $20 \mathrm{ml}$ every $2-5$ minutes, or an equivalent dose of calcium gluconate. This can be continued as an infusion in the case of severe hypotension of bradycardia [24]. Both formulations must be delivered intravenously. It seems more reasonable to administer $\mathrm{CaCl}$ via a central line to minimize the risk of skin necrosis around the site pof the intravenous catheter insertion [3]. Moreover, the administration of magnesium is important, as it is an antagonist of calcium, modulator of calcium channels activity and $\mathrm{Ca}$ ATPase and $\mathrm{Na} / \mathrm{K}$ ATPase pumps, thus stabilizes cell membranes and prevents cardiac rhythm disorders [27]. If the patient remains haemodynamically unstable after introduction of the above-mentioned therapies, one of the following treatments might be used: high-dose insulin infusion (HDI), lipid emulsion therapy or mechanical life support.

Administration of a high-dose of insulin is currently regarded as a fundamental and effective treatment of calcium channel blocker poisoning, with a success rate estimated at over $88 \%$. Nevertheless, knowledge of this treatment is deficient and based mainly on case scenarios and animal models $[28,29]$. HDI improves myocardial contractility by augmenting calcium processing, increasing glucose uptake, and inhibition of free fatty acid metabolism by stressed cardiomyocytes. Moreover, HDI acts as a vasodilator and improves microvascular dysfunction in the case of cardiovascular shock. Together, these mechanisms lead to improvement of cardiac output and may reduce the doses of catecholamines administered in cardiovascular shock $[26,29,30]$.

Commonly used HDI treatment starts at $0.5-1 \mathrm{U} / \mathrm{kg}$ insulin bolus administration, followed by $0.5-2 \mathrm{U} / \mathrm{kg} / \mathrm{h}$ infusion, and can be titrated up to $10 \mathrm{U} / \mathrm{kg} / \mathrm{h}[23,28,29]$. In some cases, even higher doses may be administered [31]. In one animal study, higher doses of therapy corresponded with better cardiac output [32]. Doses as high as $10 \mathrm{U} / \mathrm{kg} / \mathrm{h}$ have been successfully used in humans [33]. Response to HDI may take 15- 60 minutes. In this type of therapy, metabolic disturbances are likely to occur; therefore, close patient monitoring should be maintained. The main adverse effects of HDI include hypoglycaemia which occurs in about $31 \%$ of patients, and hypokalaemia in about $29 \%$ of patients. In such cases, dextrose and potassium supplementation is administered. The blood glucose level is more likely to drop when less concentrated dextrose infusions are used (50\% at $\leq 10 \%$ dextrose vs $30 \%$ at $\geq 20 \%$ dextrose) [30].

All CCBs, including verapamil, are lipophilic. Haemodialysis and haemofiltration are ineffective modes of therapy due to the large volume of CCBs distribution (5.5 l/ $\mathrm{kg}$ for verapamil) and their predilection to bind to plasma proteins [3]. Although the use of extracorporeal treatments has been suggested, the work group recommend against this method in CCBs poisoning [34]. Lipid emulsion therapy (LET) involves the intravenous injection of lipid emulsion, which creates lipid phase within the blood and binds to lipidsoluble drugs, thus reducing their volume of distribution. LET plays the role of a 'lipid sink', i.e. attracts lipophilic substances. However, there other LET's mechanisms are also known: increase of intracardiac $\mathrm{Ca}^{2+}$ concentration by affecting cardiac calcium channels, positive inotropic effect, production of alkaline $\mathrm{pH}$, and enhancement of ATP production secondary to increased concentration of intracellular fatty acid $[35,36]$. The protocol of intravenous lipid emulsion (ILE) treatment involves intralipid bolus administration of $20 \%$ at a rate of $1.5 \mathrm{ml} / \mathrm{kg}$ over minute, repeated once if needed to achieve patient clinical stability, followed by infusion of $0.25 \mathrm{ml} / \mathrm{kg} / \mathrm{min}$ over $30-60$ minutes. In cases when there is difficulty with obtaining peripheral venous access, the intraosseous line may be considered as an intermittent route [37]. In several cases, ILE was reported to improve haemodynamic parameters in patients with CCBs poisoning [38, 39]. Additionally, LET decreases verapamil serum concentration and assists with clearing them [40]. However, this therapy is based mainly on animal studies and case reports [41-43]. It is important to remember that this type of treatment may cause various analytical interferences with laboratory tests and methods [44].

Some papers provide information on drugs that lead to improvement of haemodynamic parameters in particular patients. They might find their use in the future. As for now, they may be treated as last chance therapies and can be considered on a case-to-case basis.

Levosimendan is a calcium sensitizer that increases the affinity of $\mathrm{Ca}^{2+}$ to troponin $\mathrm{C}$ without increasing intrasystolic 
calcium concentration. It has an inotropic effect on the heart and increases cardiac output, but because it is an agonist for vascular K+ATP-channels it produces peripheral vasodilatation [45]. In the rat model, levosimendan used on its own in the treatment of verapamil poisoning increased hypotension and accelerated death in animals, compared to the control group [46]. Nevertheless, it may prove to be beneficial when other treatment options are not effective or when cardiovascular shock is refractory to standard therapies; it can be used in addition to other drugs in the treatment of cardiovascular shock $[47,48]$.

4-Aminopyridine is a selective antagonist of voltage-gated $\mathrm{K}^{+}$channels, which prolongs the action potential and increases calcium influx. As a result, it enhances synaptic transmission, elevates blood pressure and improves conduction in the heart. In animal studies, 4-aminopyridine was associated with improved haemodynamic parameters, although at the risk of seizures $[49,50]$. In human studies, it was reported to improve heart rate, blood tension, and to improve some heart rhythm disturbances. However, it was usually used as the last option $[51,52]$. The doses administered to humans were smaller than those used in animal models.

Methylene blue is suggested to be a selective inhibitor of the nitric oxide-cyclic guanosine monophosphate (NOcGMP) pathway, which is believed to play a crucial role in the pathophysiology of distributive shock $[53,54]$. In animal studies, this substance alone was insufficient to contribute to the significant reduction of mortality risk. However, it increased median survival time, mean arterial pressure and heart rate [55]. It was reported that methylene blue improves haemodynamic parameters in patients suffering from drug-induced refractory vasodilatory shock [5658]. Administration of therapeutic doses, i.e. $<2 \mathrm{mg} / \mathrm{kg}$ is considered to be safe [59].

When advanced drug therapy fails to maintain life functions, life support may be taken into consideration as a bridge to recovery [60]. However, the introduction of life support such as extracorporeal membrane oxygenation may lead to bleeding, thrombosis, limb ischaemia, and other adverse effects related to this technique/may be associated with machine malfunction [61]. In certain situations, such as unstable bradycardia or high-grade AV block, especially in patients without cardiac inotropic alterations, a pacemaker can be inserted [21]. Once the patient is stabilized, it is important to arrange appropriate psychiatric evaluation and behavioural health consultation.

When an overdosed agent is known, as in the abovedescribed case, its concentration may be easily measured. Serum verapamil concentration may serve as predicting factor for mortality, where its cut-off point was set to $5.0 \mu \mathrm{M}$. Above that point, the fatality rate increases almost threefold [62]. However, in some instances, it is hard to determine the overdosed agent. Currently, research is being carried out to find a method for the identification and quantification of unknown cardiovascular drugs in both blood and urine [63]

To summarize, since in the presented case report the overdosed agent was known, the patient received specific pharmacological treatment shortly after arrival at the hospital. This prompt action proved to be sufficient in preventing circulatory collapse and maintaining the patient's vital signs. Due to the expected delayed effects of ingestion of sustainedrelease medication, the patient was monitored and treated for a prolonged time. A holistic approach to patient care, in addition to medication therapy, providing mental health care is an essential part of hospitalization. The described case shows that if reported early and properly diagnosed, even such highly hazardous situations as severe verapamil overdose, complicated by increased alcohol consumption, may be successfully treated and severe side-effects avoided. Currently, because of insufficient evidence in the literature, there is a lack of guidelines on the treatment and management of CCBs poisoning other than expert opinion recommendations. Therefore, due to the widespread availability of drugs and the increase in suicide attempts in society, it seems essential to conduct more research on this problem and develop standard procedures for managing similar cases with solid, evidencebased recommendations.

\section{CONCLUSIONS}

CCBs poisoning may have a dramatic trajectory, and treatment attempts are not successful in every case. Early initiation of correct treatment plays a crucial role in improving the chances of patient survival. It is important to remember that CCBs overdose may have different trajectories in different cases. Recognizing the symptoms of drug poisoning and performing comprehensive assessment are crucial for choosing the correct treatment options, because currently there are no readily available protocols for detecting the overdosed substance. The proposed algorithm of management in CCBs poisoning cases summarizes the available recommendations and places them in order. Nevertheless, in patients with severe intoxication these methods may be administered simultaneously (Fig. 1). In order to increase the chances of successful treatment, it is also vital to inform the specialist clinic about the case and transport the patient promptly to initiate proper management without delay. The presented case report is an example of a successful, early intervention in CCB poisoning.

\section{Funding and disclosure of conflicts of interest}

This research did not receive any specific grant from funding agencies in the public, commercial, or not-for-profit sectors. The authors have no disclosures to declare.

\section{REFERENCES}

1. Godfraind T. Discovery and Development of Calcium Channel Blockers. Front Pharmacol. 2017; 8: 286. doi: 10.3389/fphar.2017.00286

2. Rirash F, Tingey PC, Harding SE, et al. Calcium channel blockers for primary and secondary Raynaud's phenomenon. Cochrane Database Syst Rev. 2017; 12: CD000467. doi: 10.1002/14651858.CD000467.pub2

3. Chakraborty RK, Hamilton RJ. Calcium Channel Blocker Toxicity StatPearls Publishing; 2018.

4. Striessnig J, Ortner N, Pinggera A. Pharmacology of L-type Calcium Channels: Novel Drugs for Old Targets? Curr Mol Pharmacol. 2015; 8(2): 110-122. doi: 10.2174/1874467208666150507105845

5. Rorsman P, Ashcroft FM. Pancreatic $\beta$-Cell Electrical Activity and Insulin Secretion: Of Mice and Men. Physiol Rev. 2018; 98(1): 117-214. doi: 10.1152/physrev.00008.2017

6. Rizos C V, Elisaf MS. Antihypertensive drugs and glucose metabolism. World J Cardiol. 2014; 6(7): 517-530. doi: 10.4330/wjc.v6.i7.517

7. Noto H, Goto A, Tsujimoto T, Noda M. Effect of calcium channel blockers on incidence of diabetes: a meta-analysis. Diabetes Metab Syndr Obes Targets Ther. 2013; 6: 257-261. doi: 10.2147/DMSO.S49767 8. Gummin DD, Mowry JB, Beuhler MC, et al. 2019 Annual Report of the American Association of Poison Control Centers' National Poison Data System (NPDS): 37th Annual Report. Clin Toxicol. 2020; 58(12): 1360-1541. doi: 10.1080/15563650.2020.1834219 


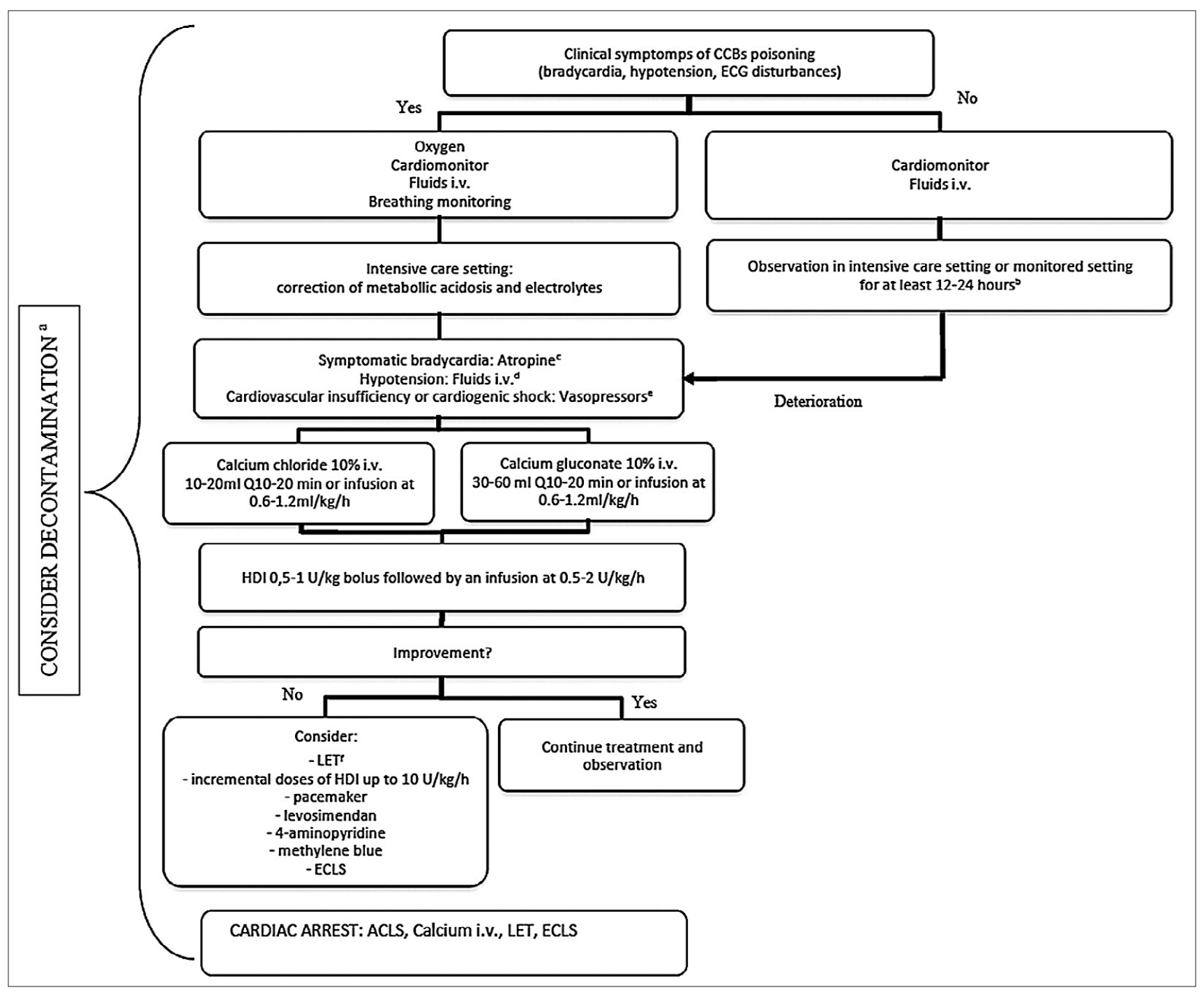

Figure 1. Algorithm of management with a patient with CCBs intoxication [21-23, 64].

a. Consider decontamination:

- sustained release CCBs or amlodypine (gastric lavage, if $<1 \mathrm{~h}$ post-ingestion, multiple-dose activated charcoal, whole-bowel irrigation);

- other CCBs (gastric lavage, if $<1 \mathrm{~h}$ post-ingestion, single-dose activated charcoal);

enteric-coated drugs, drugs not adsorbed by activated charcoal, or if $>2 \mathrm{~h}$ have passed since drug ingestion (whole bowel irrigation).

b. Longer in case of sustained release CCBs or amlodypine;

c. atropine $0.5-1.0 \mathrm{mg}$, i.v. every $2-3 \mathrm{~min}(\max 3 \mathrm{mg}$ );

d. avoid too much fluids;

e. norepinephrine is preferred (initial dose in hypotension - 50-100 nanogram/kg/min); norepinephrine, epinephrine in cardiogenic insufficiency; dobutamine, epinephrine in cardiogenic shock;

f. $20 \%$ ILE $1.5 \mathrm{ml} / \mathrm{kg}$ over 1 minute, followed by infusion of $0.25 \mathrm{ml} / \mathrm{kg} / \mathrm{min}$ over $30-60$ minutes (may be repeated).

CCBs - calcium channel blockers, HDI - high-doses insulin, ILE - intravenous lipid emulsion, LET - lipid emulsion therapy, ECLS - extracorporeal life support, ACLS advanced cardiac life support

9. Christensen MB, Petersen KM, Bøgevig S, et al. Outcomes following calcium channel blocker exposures reported to a poison information center. BMC Pharmacol Toxicol. 2018; 19. doi: 10.1186/s40360-0180271-9

10. Mandigers L, Bollen PDJ, Bijlstra PJ, Brands E. Severe verapamil intoxication despite correct use of low-dose verapamil. Drug Metab Pers Ther. 2016; 31(1): 55-58. doi: 10.1515/dmpt-2015-0041

11. Fahie S, Cassagnol M. Verapamil. StatPearls Publishing; 2019.

12. Bartlett JW, Walker PL. Management of Calcium Channel Blocker Toxicity in the Pediatric Patient. J Pediatr Pharmacol Ther JPPT. 2019; 24(5): 378-389. doi: 10.5863/1551-6776-24.5.378

13. Kline JA, Raymond RM, Schroeder JD, Watts JA. The Diabetogenic Effects of Acute Verapamil Poisoning. Toxicol Appl Pharmacol. 1997; 145(2): 357-362. doi: 10.1006/taap.1997.8195

14. Levine M, Boyer EW, Pozner CN, et al. Assessment of hyperglycemia after calcium channel blocker overdoses involving diltiazem or verapamil. Crit Care Med. 2007; 35(9): 2071-2075. doi: 10.1097/01. ccm.0000278916.04569.23
15. Siddiqi TA, Hill J, Huckleberry Y, Parthasarathy S. Non-cardiogenic pulmonary edema and life-threatening shock due to calcium channel blocker overdose: a case report and clinical review. Respir Care. 2014; 59(2): e15-21. doi: 10.4187/respcare. 02244

16.Izdes S, Altintas ND, Soykut C. Acute respiratory distress syndrome after verapamil intoxication: case report and literature review. Acta Clin Belg. 2014; 69(2): 116-119. doi: 10.1179/2295333714Y.0000000007

17. Lodhi FAK, Shogren SL, Vedre JG, Haque N, Reriani M, Ali R. Calcium Channel Blocker Toxicity Causing Acute Respiratory Distress Syndrome: A Commonly Used Drug Triggering a Life-Threatening Condition. WMJ Off Publ State Med Soc Wis. 2020; 119(1): 66-68.

18. Charpentier C, Flandrois M, Labombarda F, Maragnes P, Jokic M, Villedieu F. Intoxication aigüe au vérapamil: attention à l'effet retard. Arch Pédiatrie. 2014;21(12): 1344-1347. doi: 10.1016/j.arcped.2014.09.013

19. Tuka V, Ricarova B, Janota T, Malik J, Kotrlikova E. Surprisingly delayed escalation of severe verapamil poisoning. Eur J Emerg Med. 2009; 16(2): 100-102. doi: 10.1097/MEJ.0b013e32830a997c 
20. Chan L-N, Anderson GD. Pharmacokinetic and pharmacodynamic drug interactions with ethanol (alcohol). Clin Pharmacokinet. 2014; 53(12): 1115-1136. doi: 10.1007/s40262-014-0190-x

21. St-Onge M, Anseeuw K, Cantrell FL, et al. Experts Consensus Recommendations for the Management of Calcium Channel Blocker Poisoning in Adults. Crit Care Med. 2017; 45(3): e306-e315. doi: 10.1097/ CCM.0000000000002087

22. Mégarbane B, Oberlin M, Alvarez J-C, et al. Management of pharmaceutical and recreational drug poisoning. Ann Intensive Care. 2020; 10(1): 157. doi: 10.1186/s13613-020-00762-9

23. Rietjens SJ, de Lange DW, Donker DW, Meulenbelt J. Practical recommendations for calcium channel antagonist poisoning. Neth J Med. 2016; 74(2): 8.

24. Truhlář A, Deakin CD, Soar J, et al. European Resuscitation Council Guidelines for Resuscitation 2015. Resuscitation. 2015; 95: 148-201. doi: 10.1016/j.resuscitation.2015.07.017

25. Thanacoody R, Caravati EM, Troutman B, et al. Position paper update: Whole bowel irrigation for gastrointestinal decontamination of overdose patients. Clin Toxicol. 2015; 53(1): 5-12. doi: $10.3109 / 15563650.2014 .989326$

26. Lashari BH, Minalyan A, Khan W, Naglak M, Ward W. The Use of High-dose Insulin Infusion and Lipid Emulsion Therapy in Concurrent Beta-blocker and Calcium Channel Blocker Overdose. Cureus. 2018; 10(11): e3534. doi: 10.7759/cureus.3534

27. Dubé L, Granry JC. The therapeutic use of magnesium in anesthesiology, intensive care and emergency medicine: a review. Can J Anaesth. 2003 Aug-Sep; 50(7): 732-46. doi: 10.1007/BF03018719. PMID: 12944451.

28. Woodward C, Pourmand A, Mazer-Amirshahi M. High dose insulin therapy, an evidence based approach to beta blocker/calcium channel blocker toxicity. Daru J Fac Pharm Tehran Univ Med Sci. 2014; 22(1): 36. doi: 10.1186/2008-2231-22-36

29. Krenz JR, Kaakeh Y. An Overview of Hyperinsulinemic-Euglycemic Therapy in Calcium Channel Blocker and $\beta$-blocker Overdose. Pharmacother J Hum Pharmacol Drug Ther. 2018; 38(11): 1130-1142. doi: 10.1002/phar.2177

30. Cole JB, Arens AM, Laes JR, Klein LR, Bangh SA, Olives TD. High dose insulin for beta-blocker and calcium channel-blocker poisoning. Am J Emerg Med. 2018; 36(10): 1817-1824. doi: 10.1016/j.ajem.2018.02.004

31. Walter E, McKinlay J, Corbett J, Kirk-Bayley J. Review of management in cardiotoxic overdose and efficacy of delayed intralipid use. J Intensive Care Soc. 2018; 19(1): 50-55. doi: 10.1177/1751143717705802

32. Cole JB, Stellpflug SJ, Ellsworth H, et al. A blinded, randomized, controlled trial of three doses of high-dose insulin in poisoninduced cardiogenic shock. Clin Toxicol. 2013; 51(4): 201-207. doi: $10.3109 / 15563650.2013 .770152$

33. Holger JS, Stellpflug SJ, Cole JB, Harris CR, Engebretsen KM. High-dose insulin: A consecutive case series in toxin-induced cardiogenic shock. Clin Toxicol. 2011; 49(7): 653-658. doi: 10.3109/15563650.2011.593522

34. Wong A, Hoffman RS, Walsh SJ, et al. Extracorporeal treatment for calcium channel blocker poisoning: systematic review and recommendations from the EXTRIP workgroup. Clin Toxicol. 2021; 0(0): 1-31. doi: 10.1080/15563650.2020.1870123

35. Lashari BH, Minalyan A, Khan W, Naglak M, Ward W. The Use of High-dose Insulin Infusion and Lipid Emulsion Therapy in Concurrent Beta-blocker and Calcium Channel Blocker Overdose. Cureus. 2018; 10(11): e3534. doi: 10.7759/cureus.3534

36. Ciechanowicz S, Patil V. Lipid emulsion for local anesthetic systemic toxicity. Anesthesiol Res Pract. 2012; 2012: 131784. doi: $10.1155 / 2012 / 131784$

37. Sampson CS, Bedy S-M. Lipid emulsion therapy given intraosseously in massive verapamil overdose. Am J Emerg Med. 2015; 33(12): 1844 e1. doi: 10.1016/j.ajem.2015.04.061

38. Doepker B, Healy W, Cortez E, Adkins EJ. High-Dose Insulin and Intravenous Lipid Emulsion Therapy for Cardiogenic Shock Induced by Intentional Calcium-Channel Blocker and Beta-Blocker Overdose: A Case Series. J Emerg Med. 2014; 46(4): 486-490. doi: 10.1016/j. jemermed.2013.08.135

39. Young AC, Velez LI, Kleinschmidt KC. Intravenous fat emulsion therapy for intentional sustained-release verapamil overdose. Resuscitation. 2009; 80(5): 591-593. doi: 10.1016/j.resuscitation.2009.01.023

40. French D, Armenian P, Ruan W, et al. Serum verapamil concentrations before and after Intralipid ${ }^{\star}$ therapy during treatment of an overdose. Clin Toxicol. 2011; 49(4): 340-344. doi: 10.3109/15563650.2011.572556

41. Kang C, Kim DH, Kim SC, et al. The effects of intravenous lipid emulsion on prolongation of survival in a rat model of calcium channel blocker toxicity. Clin Toxicol. 2015; 53(6): 540-544. doi: $10.3109 / 15563650.2015 .1045979$
42. Sebe A, Dişel NR, Açıkalın Akpınar A, Karakoç E. Role of intravenous lipid emulsions in the management of calcium channel blocker and $\beta$-blocker overdose: 3 years experience of a university hospital. Postgrad Med. 2015; 127(2): 119-124. doi: 10.1080/00325481.2015.1012480

43. Levine M, Hoffman RS, Lavergne V, et al. Systematic review of the effect of intravenous lipid emulsion therapy for non-local anesthetics toxicity. Clin Toxicol. 2016; 54(3): 194-221. doi: 10.3109/15563650.2015.1126286

44. Cao D, Heard K, Foran M, Koyfman A. Intravenous lipid emulsion in the emergency department: a systematic review of recent literature. J Emerg Med. 2015; 48(3): 387-397. doi: 10.1016/j.jemermed.2014.10.009

45. Pathak A, Lebrin M, Vaccaro A, Senard JM, Despas F. Pharmacology of levosimendan: inotropic, vasodilatory and cardioprotective effects. J Clin Pharm Ther. 2013; 38(5): 341-349. doi: 10.1111/jcpt.12067

46. Abraham MK, Scott SB, Meltzer A, Barrueto F. Levosimendan does not improve survival time in a rat model of verapamil toxicity. J Med Toxicol Off J Am Coll Med Toxicol. 2009; 5(1): 3-7.

47. Osthoff M, Bernsmeier C, Marsch SC, Hunziker PR. Levosimendan as treatment option in severe verapamil intoxication: a case report and review of the literature. Case Rep Med. 2010; 2010. doi: $10.1155 / 2010 / 546904$

48. Glinka L, Mayzner-Zawadzka E, Onichimowski D, Jalali R, Glinka M. Levosimendan in the modern treatment of patients with acute heart failure of various aetiologies. Arch Med Sci AMS. 2019; 17(2): 296-303. doi: 10.5114/aoms.2018.77055

49. St-Onge M, Dubé P-A, Gosselin S, et al. Treatment for calcium channel blocker poisoning: a systematic review. Clin Toxicol Phila Pa. 2014; 52(9): 926-944. doi: 10.3109/15563650.2014.965827

50. Bellou A, Al-Hammadi S, Aburawi EH, et al. 4-Aminopyridine, A Blocker of Voltage-Dependent K+ Channels, Restores Blood Pressure and Improves Survival in the Wistar Rat Model of Anaphylactic Shock. Crit Care Med. 2016; 44(11): e1082-e1089. doi: 10.1097/ CCM.0000000000001822

51.Fiszer M, Kołaciński Z, Rechciński T. [The application of 4-aminopyridine in calcium channel inhibitors acute poisoning]. Przegl Lek. 2007; 64(4-5): 293-297.

52. Magdalan J, Kochman K, Antończyk A, Przewłocki M, Smolarek M. [Successful treatment by 4--aminopyridine of three cases of severe verapamil poisoning]. Przegl Lek. 2003; 60(4): 271-273.

53. Warrick BJ, Tataru AP, Smolinske S. A systematic analysis of methylene blue for drug-induced shock. Clin Toxicol. 2016; 54(7): 547-555. doi: 10.1080/15563650.2016.1180390

54. Jang DH, Nelson LS, Hoffman RS. Methylene Blue for Distributive Shock: A Potential New Use of an Old Antidote. J Med Toxicol. 2013; 9(3): 242-249. doi: 10.1007/s13181-013-0298-7

55. Jang DH, Donovan S, Nelson LS, Bania TC, Hoffman RS, Chu J. Efficacy of Methylene Blue in an Experimental Model of Calcium Channel Blocker-Induced Shock. Ann Emerg Med. 2015; 65(4): 410-415. doi: 10.1016/j.annemergmed.2014.09.015

56. Ahmed S, Barnes S. Hemodynamic improvement using methylene blue after calcium channel blocker overdose. World J Emerg Med. 2019; 10(1): 55-58. doi: 10.5847/wjem.j.1920-8642.2019.01.009

57. Laes JR, Williams DM, Cole JB. Improvement in Hemodynamics After Methylene Blue Administration in Drug-Induced Vasodilatory Shock: A Case Report. J Med Toxicol. 2015; 11(4): 460-463. doi: 10.1007/ s13181-015-0500-1

58. Saha BK, Bonnier A, Chong W. Rapid reversal of vasoplegia with methylene blue in calcium channel blocker poisoning. Afr J Emerg Med Rev Afr Med Urgence. 2020; 10(4): 284-287. doi: 10.1016/j. afjem.2020.06.014

59. Ginimuge PR, Jyothi SD. Methylene blue: revisited. J Anaesthesiol Clin Pharmacol. 2010; 26(4): 517-520.

60. Groot M, Grewal S, Meeder H, Thiel R, den Uil C. Extracorporeal life support in calcium antagonist intoxication. Ned Tijdschr Geneeskd. 2017; 161: D1960.

61. de Lange DW, Sikma MA, Meulenbelt J. Extracorporeal membrane oxygenation in the treatment of poisoned patients. Clin Toxicol Phila Pa. 2013; 51(5): 385-393. doi: 10.3109/15563650.2013.800876

62. Mégarbane B, Karyo S, Abidi K, et al. Predictors of Mortality in Verapamil Overdose: Usefulness of Serum Verapamil Concentrations. Basic Clin Pharmacol Toxicol. 2011; 108(6): 385-389. doi: 10.1111/j.17427843.2010.00666.x

63. Morini L, Moretti M, Brandolini F, Osculati AMM, Groppi A, Vignali C. Two Fatal Cases Involving Cardiovascular Drugs Diltiazem and Amlodipine. J Anal Toxicol. 2018; 42(1): e15-e19. doi: 10.1093/jat/bkx087

64. Szpak D. Zatrucia lekami i innymi ksenobiotykami działającymi na układ krążenia. In: Jurowski K, Piekoszewski, editors. Toksykologia. Ed. 1. Warszawa; 2020. p. 418-424. 